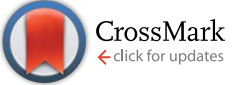

Cite this: RSC Adv., 2017, 7, 12351

Received 28th December 2016 Accepted 14th February 2017

DOI: $10.1039 / c 6 r a 28789 a$

rsc.li/rsc-advances

\title{
Manganese dioxide nanowires on carbon nanofiber frameworks for efficient electrochemical device electrodes $\dagger$
}

\author{
Y. Saito, ${ }^{a}$ M. Meguro, ${ }^{a}$ M. Ashizawa, ${ }^{a}$ K. Waki, ${ }^{b}$ R. Yuksel, ${ }^{c}$ H. E. Unalan ${ }^{d}$ \\ and $\mathrm{H}$. Matsumoto*a
}

\begin{abstract}
Hierarchically nanostructured composite electrodes were prepared by the electrodeposition of manganese dioxide nanowires ( $\mathrm{MnO}_{2} \mathrm{NWs}$ ) with 5-20 nm diameters on electrospun carbon nanofiber (CNF) webs with diameters of 250 and $650 \mathrm{~nm}$. The effects of CNF diameters and mass loading of $\mathrm{MnO}_{2} \mathrm{NWs}$ on the hierarchical nanostructure formation and the performance of the composite electrodes were investigated. The internal structure of the composite electrode depended on CNF diameter and mass loading of $\mathrm{MnO}_{2} \mathrm{NW}$. The electrodes based on thinner CNFs and higher mass loadings of $\mathrm{MnO}_{2} \mathrm{NWs}$ showed higher values of gravimetric and volumetric capacitances. This would be due to $\mathrm{MnO}_{2} \mathrm{NWs}$ forming a dense network in the thinner three-dimensional CNF framework. In addition, asymmetric supercapacitors with the $\mathrm{MnO}_{2} \mathrm{NW} / \mathrm{CNF}$ composite electrode as the positive electrode and activated carbon as the negative electrode showed high energy and power densities of $8.9 \mathrm{~W} \mathrm{~h} \mathrm{~kg} \mathrm{and}^{-1} .9 \mathrm{~kW}$ $\mathrm{kg}^{-1}$, respectively. These results clearly indicate that the hierarchical network nanostructure composed of an active material and a charge collector can be considered a promising electrode for various electrochemical devices.
\end{abstract}

\section{Introduction}

To improve the capacity of electrochemical supercapacitors, a wide range of metal oxides such as ruthenium oxide $\left(\mathrm{RuO}_{2}\right),{ }^{1,2}$ manganese dioxide $\left(\mathrm{MnO}_{2}\right),{ }^{3}$ vanadium oxide $\left(\mathrm{V}_{2} \mathrm{O}_{5}\right),{ }^{4}$ and nickel oxide $(\mathrm{NiO})^{5}$ have been investigated as the active electrode materials and show promising characteristics. Among them, $\mathrm{MnO}_{2}$ with its high theoretical specific capacitance (1370 $\mathrm{F}^{-1}$ ), natural abundance and environmental friendliness, as well as low cost, has received considerable attention. ${ }^{6}$ However, it is known that $\mathrm{MnO}_{2}$ shows a high specific capacitance only at very low loadings (about a few $\mu \mathrm{g} \mathrm{cm}^{-2}$ ) on the current collector due to its extremely low electrical conductivity $\left(10^{-5}\right.$ to $10^{-6} \mathrm{~S}$ $\left.\mathrm{cm}^{-1}\right) .{ }^{3,6-8}$ Therefore, the development of high specific capacitance electrodes with $\mathrm{MnO}_{2}$ is still a challenge. To overcome this issue, many approaches, such as doping of $\mathrm{MnO}_{2},{ }^{9}$

${ }^{a}$ Department of Materials Science and Engineering, Tokyo Institute of Technology, 2-12-1 Ookayama, Meguro-ku, Tokyo 152-8552, Japan. E-mail: matsumoto.h.ac@m. titech.ac.jp

${ }^{b}$ Department of Chemical Science and Engineering, Tokyo Institute of Technology, 4259, Nagatsuta-cho, Midori-ku, Yokohama-shi 226-8502, Japan

'Department of Micro and Nanotechnology, Middle East Technical University, Ankara 06800, Turkey

${ }^{d}$ Department of Metallurgical and Materials Engineering, Middle East Technical University, 06800 Ankara, Turkey

$\dagger$ Electronic supplementary information (ESI) available. See DOI: $10.1039 / \mathrm{c} 6 \mathrm{ra} 28789 \mathrm{a}$ nanofabrication of $\mathrm{MnO}_{2},{ }^{10}$ and composite formation using conductive materials ${ }^{\mathbf{1 1}, \mathbf{1 2}}$ have been taken. In particular, formation of composite electrodes using nanostructured $\mathrm{MnO}_{2}$ and conductive carbonaceous materials have attracted much attention. ${ }^{\mathbf{1 3 - 1 6}}$ For example, several researchers reported $\mathrm{MnO}_{2}$ electrodes mixed with carbon microfibers, ${ }^{17}$ carbon nanotubes $(\mathrm{CNT}){ }^{18,19}$ graphene $^{20-22}$ and a CNT/graphene complex. ${ }^{23,24}$

Herein, we fabricated hierarchically nanostructured composite electrodes, $\mathrm{MnO}_{2}$ nanowires $\left(\mathrm{MnO}_{2} \mathrm{NWs}\right)$ on carbon nanofiber (CNF) webs. The hierarchical nanostructure allows efficient charge collection through the three-dimensional (3-D) CNF framework (Fig. 1). Therefore, it is expected that this composite electrodes can simultaneously achieve high capacitance and rapid charge and discharge due to the high mass loading of the $\mathrm{MnO}_{2}$ NWs on the conductive CNF webs with high surface area. In the present study, $\mathrm{MnO}_{2} \mathrm{NW} / \mathrm{CNF}$ composite electrodes were prepared by the electrodeposition of $\mathrm{MnO}_{2} \mathrm{NWs}$ with various mass loadings on the electrospun CNFs with diameters of 250 and $650 \mathrm{~nm}$. We investigated the effects of CNF diameters and mass loadings of $\mathrm{MnO}_{2} \mathrm{NWs}$ on the hierarchical nanostructure formation and the performance of the composite electrodes. In addition, we fabricated asymmetric supercapacitor (ASC) devices with the $\mathrm{MnO}_{2} \mathrm{NW} / \mathrm{CNF}$ composite electrode as the positive electrode and activated carbon (AC) as the negative electrode and evaluated their performance. 


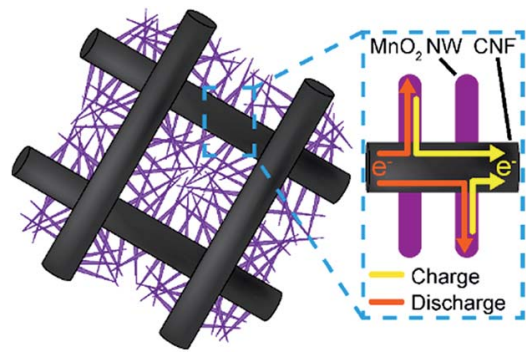

Fig. 1 Schematic of hierarchically nanostructured composite electrode, $\mathrm{MnO}_{2} \mathrm{NWs}$ on CNF web.

\section{Experimental procedure}

\section{Materials}

Polyacrylonitrile (PAN, $M_{\mathrm{w}}=150000$ ) was purchased from Sigma-Aldrich, USA. $N, N$-Dimethylformamide (DMF) of extrapure grade and manganese(II) acetate tetrahydrate $\left(\left(\mathrm{CH}_{3}-\right.\right.$ $\left.\mathrm{COO})_{2} \mathrm{Mn} \cdot 4 \mathrm{H}_{2} \mathrm{O}\right)$ ) of extra-pure grade were obtained from Wako Pure Chemical Industries, Japan. Sodium sulfate of extra-pure grade and hydrochloric acid of extrapure grade were obtained from Kanto Chemical, Japan. These reagents were used without further purification. Activated carbon sheet (AC sheet, the specific capacitance is $82.2 \mathrm{~F} \mathrm{~g}^{-1}$ at $1.0 \mathrm{~A} \mathrm{~g}^{-1}$ ) was obtained from Nippon Valqua Industries, Japan.

\section{Preparation of CNF webs}

The CNF webs were prepared by electrospinning of a precursor polymer solution and successive stabilization and carbonization. ${ }^{25-27}$ Polyacrylonitrile (PAN) was used as the carbon precursor. ${ }^{28}$ For preparation of the spinning solution, PAN was dissolved in DMF to give 10 and 15 wt\% PAN/DMF solutions. The electrospinning device was the same as that used in our previous study. ${ }^{29}$ The polymer solution was contained in a syringe with a stainless steel nozzle $(0.21 \mathrm{~mm}$ internal diameter). The nozzle was connected to a high-voltage regulated DC power supply (HJPQ-30P1, Matsusada Precision, Japan). A constant volume flow rate was maintained by a syringe-type infusion pump (MCIP-III, Minato Concept, Japan). An aluminum plate $\left(10 \times 10 \mathrm{~cm}^{2}\right)$ was used as the collector for the electrospun fibers. The distance between the nozzle tip and the collector were 10 and $15 \mathrm{~cm}$ for the 10 and $15 \mathrm{wt} \%$ solutions, respectively. The applied voltage was $8 \mathrm{kV}$, and the flow rate was $5 \mu \mathrm{L} \mathrm{min}{ }^{-1}$. All spinnings were carried out at $25 \pm 3{ }^{\circ} \mathrm{C}$ and at a relative humidity value of less than $60 \%$. The as-spun PAN nanofibers were heated at $230{ }^{\circ} \mathrm{C}$ for $3 \mathrm{~h}$ in air for stabilizing, then they were heated at $1000{ }^{\circ} \mathrm{C}$ for $1 \mathrm{~h}$ in a nitrogen atmosphere for carbonization.

\section{Preparation of $\mathrm{MnO}_{2} \mathrm{NW} / \mathrm{CNF}$ composite electrodes}

The $\mathrm{MnO}_{2} \mathrm{NW} / \mathrm{CNF}$ composite electrodes were prepared by electrodeposition of the $\mathrm{MnO}_{2}$ NWs onto the CNF surfaces. Before the deposition, the CNF webs were sufficiently washed with acetone (Ac) and deionized water (DIW) to remove any contaminants. Subsequently, the CNF webs were soaked in a $0.1 \mathrm{M}$ hydrochloric acid solution for $10 \mathrm{~min}$ for the surface modification with hydrophilic groups, washed thoroughly by DIW, then dried at $100{ }^{\circ} \mathrm{C}$ for $3 \mathrm{~h}$ under vacuum. Before electrodeposition, the CNF webs were cut into small pieces $(1 \mathrm{~cm} \times$ $2 \mathrm{~cm})$ and the cut samples were immersed overnight in the mixed solution of Ac and DIW (Ac : DIW $=1: 1 \mathrm{v} / \mathrm{v}$ ) in order to promote infiltration of the electrodeposition solution. $\mathrm{MnO}_{2}$ NWs were then deposited through the application of a constant voltage of $0.4 \mathrm{~V}(v s$. $\mathrm{Ag} / \mathrm{AgCl}$ sat.) in a solution containing $0.1 \mathrm{M}$ $\left(\mathrm{CH}_{3} \mathrm{COO}\right)_{2} \mathrm{Mn} \cdot 4 \mathrm{H}_{2} \mathrm{O}$ and $0.1 \mathrm{M}$ sodium sulfate $\left(\mathrm{Na}_{2} \mathrm{SO}_{4}\right)$ at room temperature. The electrodepositions were carried out in a three-electrode cell with the CNF web as the working electrode, platinum mesh as the counter electrode, and a saturated $\mathrm{Ag} / \mathrm{Ag} \mathrm{Cl}$ electrode (DKK-TOA, Japan) as the reference electrode. The mass loading of the $\mathrm{MnO}_{2}$ NWs was controlled by the charge passed at the range of $0.22,0.55,2.1$ and $4.2 \mathrm{C} \mathrm{cm}^{-2}$. After the deposition, the electrodes were removed from the electrodeposition solution and carefully washed with DIW to remove any excess electrolyte, then dried at $100{ }^{\circ} \mathrm{C}$ for $3 \mathrm{~h}$ under vacuum.

\section{Characterization}

The electrical conductivities along the surface direction of the CNF webs were measured by a four-point probe method using a low resistivity meter (Loresta-GP MCP-T610, Mitsubishi Chemical Analytech, Japan). The morphological characterization of the prepared composite electrodes were made by a fieldemission scanning electron microscope (FE-SEM, S4700, Hitachi, Japan), a scanning electron microscope (SEM, JCM-5700, JEOL, Japan), and a transmission electron microscope (TEM, JEM-2010F, JEOL, Japan) operated at $100 \mathrm{kV}$. The pore size distribution of the $\mathrm{MnO}_{2} \mathrm{NW} / \mathrm{CNF}$ composite electrodes was determined by mercury porosimetry measurements using an instrument (Auto Pore IV 9520, Micrometrics, USA). The crystal structure of the $\mathrm{MnO}_{2} \mathrm{NWs}$ was determined by an X-ray diffractometer (XRD, X'Pert-MPD, Philips, Netherlands). X-ray photoelectron spectroscopy (XPS) was conducted by an instrument (JPS-9010MC, JEOL, Japan) equipped with a monochromator using an $\mathrm{Al}$ anode $(12 \mathrm{kV}, 25 \mathrm{~mA})$. The acquired spectra were charge-corrected using the Mn $2 \mathrm{p}(3 / 2)$ signal at $642.0 \mathrm{eV}$.

\section{Electrochemical measurements}

The electrochemical measurements of the $\mathrm{MnO}_{2} \mathrm{NW} / \mathrm{CNF}$ composite electrodes were carried out using a potentiostat/ galvanostat (SI 1287, Solartron ISA, UK), and a frequency response analyzer (1255B, Solartoron ISA, UK). The electrochemical characteristics of the prepared $\mathrm{MnO}_{2} \mathrm{NW} / \mathrm{CNF}$ composite electrodes were determined by galvanostatic charge/ discharge measurements in a three-electrode cell for plate-type electrodes (ALS, Japan). The composite electrode was used as the working electrode, platinum wire as the counter electrode, the $\mathrm{Ag} / \mathrm{AgCl}$ electrode ( $3 \mathrm{M}$ sodium chloride, $\mathrm{NaCl}$ ) as the reference electrode, and a $1 \mathrm{M} \mathrm{Na}_{2} \mathrm{SO}_{4}$ solution as the electrolyte. Prior to the measurements, the composite electrode was soaked in the mixed solution of Ac and DIW (Ac: DIW $=1: 1 \mathrm{v} / \mathrm{v}$ ) for $1 \mathrm{~h}$, then soaked overnight in a $1 \mathrm{M} \mathrm{Na}_{2} \mathrm{SO}_{4}$ solution. 
(a)

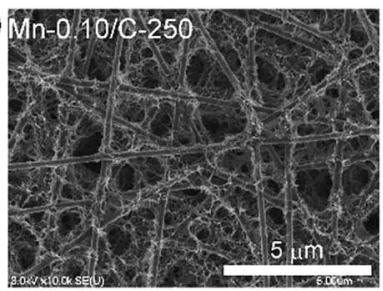

(e)

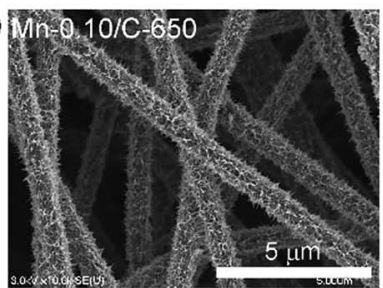

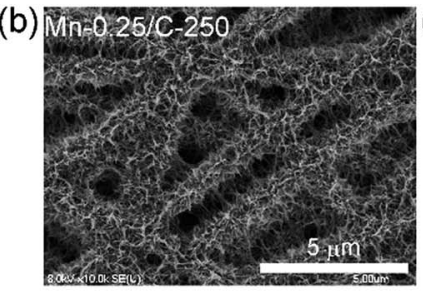
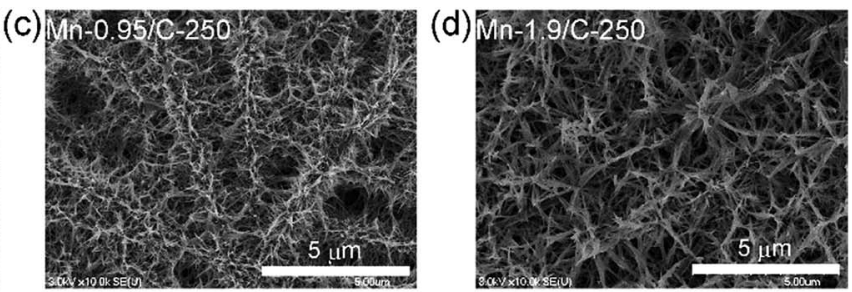

(f) $\mathrm{Mn}-0,25 / \mathrm{C}-650$
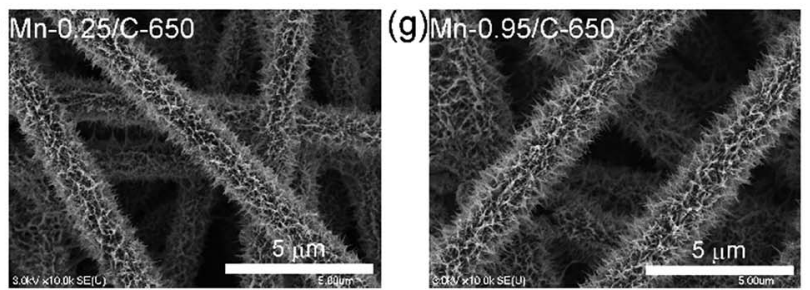

(h) $\operatorname{Mn}-1.9 / \mathrm{C}-650$

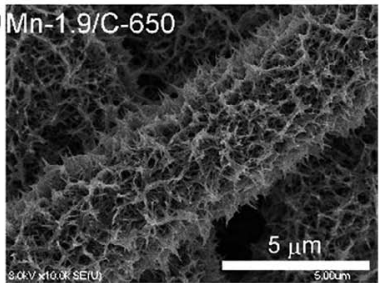

Fig. 2 Surface SEM images of $\mathrm{MnO}_{2}$ NW/CNF composite electrodes with various mass loading: (a) Mn-0.10/C-250, (b) Mn-0.25/C-250, (c) Mn0.95/C-250, (d) Mn-1.9/C-250, (e) Mn-0.10/C-650, (f) Mn-0.25/C-650, (g) Mn-0.95/C-650, and (h) Mn-1.9/C-650.

\section{Fabrication and evaluation of the asymmetric supercapacitor} devices

The ASC devices were fabricated using a two-electrode cell (Hosen, Japan) with the $\mathrm{MnO}_{2} \mathrm{NW} / \mathrm{CNF}$ composite electrode as the positive electrode, an $\mathrm{AC}$ sheet as the negative electrode, Whatman cellulose filter as the separator between the two electrodes and a $1 \mathrm{M} \mathrm{Na}_{2} \mathrm{SO}_{4}$ solution as the electrolyte.

\section{Results and discussion}

Preparation and characterization of CNF webs and $\mathrm{MnO}_{2} \mathrm{NW} /$ CNF composite electrodes

The CNF webs with average diameters $(D)$ of $256 \pm 24 \mathrm{~nm}(\mathrm{C}-250)$ and $667 \pm 33 \mathrm{~nm}$ (C-650) were prepared by electrospinning from the 10 and $15 \mathrm{wt} \%$ PAN/DMF solutions, respectively, followed by successive carbonization (Fig. S1† shows SEM images of the prepared CNF webs and their diameter distribution). Thicknesses of the prepared webs were approximately $30 \mu \mathrm{m}$. C-250 and C-650 showed comparable apparent surface electric conductivities of 7.5 and $6.2 \mathrm{~S} \mathrm{~cm}^{-1}$, respectively (Table S1†). ${ }^{30}$

Table 1 Structural characteristics of $\mathrm{MnO}_{2}$ NW/CNF composite electrodes

\begin{tabular}{|c|c|c|c|c|}
\hline \multirow{2}{*}{$\begin{array}{l}\text { Specific mass } \\
\text { loading }\left(\mathrm{mg} \mathrm{cm}^{-2}\right)\end{array}$} & \multicolumn{2}{|c|}{$\begin{array}{l}\text { Thickness of } \mathrm{MnO}_{2} \mathrm{NW} \\
\text { layer }^{a}(\mu \mathrm{m})\end{array}$} & \multicolumn{2}{|c|}{$\begin{array}{l}\mathrm{MnO}_{2} \text { content } \\
(\mathrm{wt} \%)\end{array}$} \\
\hline & C- -250 & C-650 & C-250 & C-650 \\
\hline 0.10 & - & $0.16 \pm 0.06$ & 46.5 & 20.8 \\
\hline 0.25 & $0.17 \pm 0.03$ & $0.98 \pm 0.15$ & 59.3 & 59.1 \\
\hline 0.95 & - & $1.26 \pm 0.15$ & 81.0 & 77.9 \\
\hline 1.9 & - & $2.02 \pm 0.24$ & 84.7 & 86.3 \\
\hline
\end{tabular}

${ }^{a}$ The thickness of the $\mathrm{MnO}_{2}$ NW layer was determined from SEM analysis on average of 50 points. The $\mathrm{MnO}_{2} \mathrm{NW}$ layer thickness of $\mathrm{Mn} / \mathrm{C}-250 \mathrm{~s}$ at $0.10,0.95$ and $1.9 \mathrm{mg} \mathrm{cm}^{-2}$ could not be determined, because $\mathrm{MnO}_{2}$ NWs were partially deposited on the CNF surface at $0.10 \mathrm{mg} \mathrm{cm}{ }^{-2}$ and $\mathrm{MnO}_{2}$ NWs formed network structure in the interfiber space of the CNF framework.
$\mathrm{MnO}_{2}$ NWs with the mass loading of $0.10,0.25,0.95$, and $1.9 \mathrm{mg} \mathrm{cm}^{-2}$ were successfully deposited onto the CNF webs by changing the charge amounts based on eqn (1). Hereafter, the

(a)

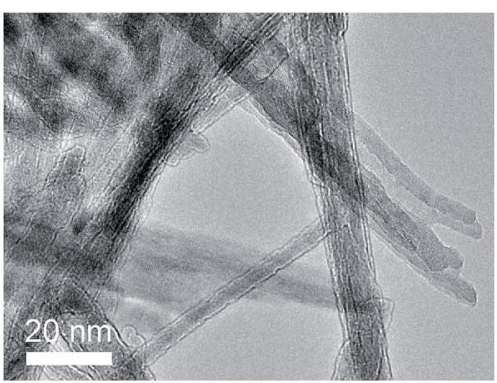

(b)

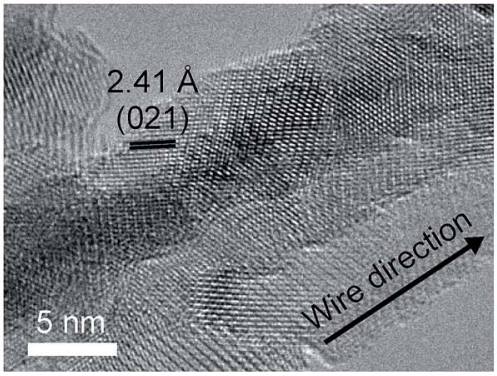

(c)

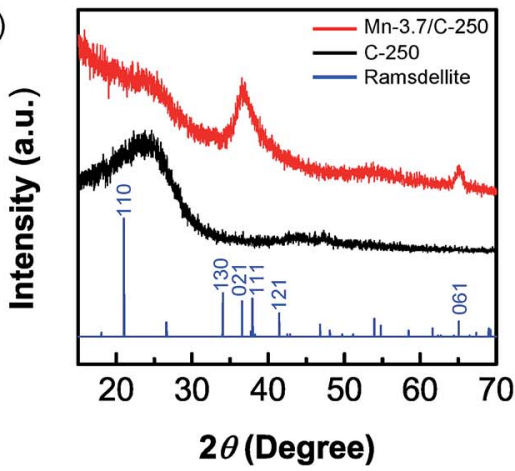

Fig. 3 (a) TEM image of $\mathrm{MnO}_{2} \mathrm{NWs}$ on $\mathrm{Mn}-0.95 / \mathrm{C}-250$ electrode. (b) Higher magnification image of (a). (c) XRD patterns of $\mathrm{Mn}-3.7 / \mathrm{C}-250$ electrode, C-250, and ramsdellite (ICDD: 042-1316). 
prepared electrodes will be referred as Mn(-mass loading)/C(-CNF diameter) (e.g., Mn-0.10/C-250).

$$
\mathrm{Mn}^{2+}+2 \mathrm{H}_{2} \mathrm{O} \rightarrow \mathrm{MnO}_{2}+4 \mathrm{H}^{+}+2 \mathrm{e}^{-}
$$

Fig. 2 shows SEM images of the $\mathrm{MnO}_{2} \mathrm{NW} / \mathrm{CNF}$ composite electrodes with various mass loadings. For the Mn/C-250s, $\mathrm{MnO}_{2}$ NWs mainly grew on the intersection points of CNF framework at the small mass loading of $0.10 \mathrm{mg} \mathrm{cm} \mathrm{cm}^{-2}$ (Fig. 2(a)). With an increase in the mass loading, $\mathrm{MnO}_{2} \mathrm{NWs}$ covered the surface of the CNFs and formed a layer structure (@) $0.25 \mathrm{mg} \mathrm{cm}^{-2}$, Fig. 2(b)). Finally, $\mathrm{MnO}_{2} \mathrm{NWs}$ were densely grown and formed a network structure in the inter-fiber space of the CNF framework (@0.95 and $1.9 \mathrm{mg} \mathrm{cm}^{-2}$, Fig. 2(c) and (d), respectively): hierarchical network nanostructures composed of an active material and a charge collector was formed. On the other hand, for the Mn/C-650s (Fig. 2(e-h)), $\mathrm{MnO}_{2} \mathrm{NW}$ did not form a network structure, but formed a thick layer on the surface of CNF at the higher mass loading (Table 1). The difference in the hierarchical structure between $\mathrm{Mn} / \mathrm{C}-250$ s and $\mathrm{Mn} / \mathrm{C}-650 \mathrm{~s}$ is due to the differences in the surface area and the size of inter-fiber space between CNF frameworks.

The TEM images demonstrate that $\mathrm{MnO}_{2}$ NWs grown on all the electrodes have high aspect ratios (several hundred nanometers in length and 5-20 $\mathrm{nm}$ in diameter). The $\mathrm{MnO}_{2} \mathrm{NWs}$ were composed of aggregations of needle-like fine crystals with individual diameters of 2-5 nm (Fig. 3(a) and (b)). To identify the crystal structure of the $\mathrm{MnO}_{2} \mathrm{NWs}$, a large amount of $\mathrm{MnO}_{2}$ NWs $\left(3.7 \mathrm{mg} \mathrm{cm}^{-2}\right)$ were deposited onto C-250 electrode. The

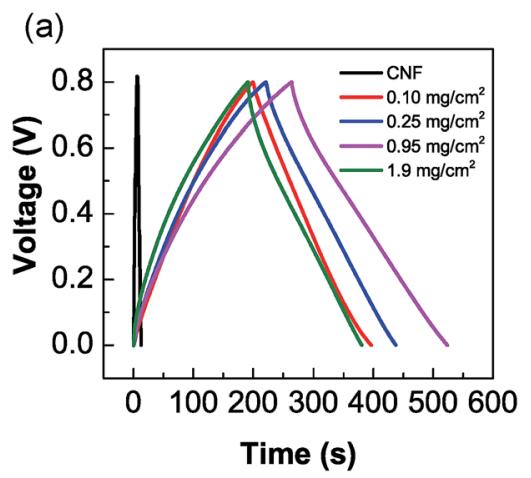

(b)

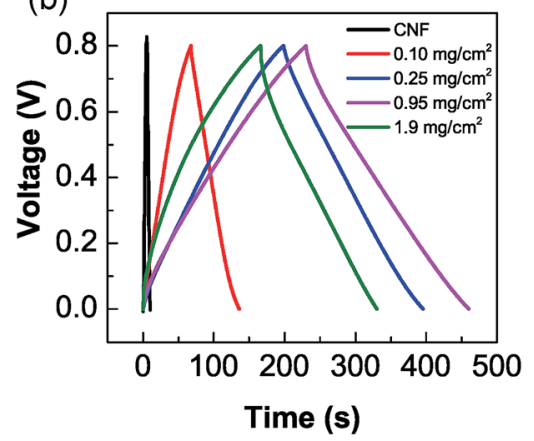

Fig. 4 Charge-discharge curves of (a) Mn/C-250 and (b) Mn/C-650 composite electrodes with various mass loadings at a current density of $0.5 \mathrm{~A} \mathrm{~g}^{-1}$
Table 2 Specific capacitance of $\mathrm{MnO}_{2} \mathrm{NW} / \mathrm{CNF}$ composite electrodes at a current density of $0.5 \mathrm{~A} \mathrm{~g}^{-1}$

\begin{tabular}{|c|c|c|c|c|c|c|}
\hline \multirow{2}{*}{$\begin{array}{l}\text { Specific mass } \\
\text { loading }\left(\mathrm{mg} \mathrm{cm}^{-2}\right)\end{array}$} & \multicolumn{2}{|c|}{$C_{\mathrm{g}}\left(\mathrm{F} \mathrm{g}^{-1}\right)$} & \multicolumn{2}{|c|}{$C_{\mathrm{v}}\left(\mathrm{F} \mathrm{cm}^{-3}\right)$} & \multicolumn{2}{|c|}{$\begin{array}{l}C_{\mathrm{g}}-\mathrm{MnO}_{2} \\
\left(\mathrm{~F} \mathrm{~g}^{-1}\right) \\
\end{array}$} \\
\hline & C-250 & C-650 & C-250 & C-650 & C-250 & C-650 \\
\hline 0.10 & 124 & 43.4 & 18.7 & 10.6 & 266 & 209 \\
\hline 0.25 & 134 & 123 & 48.1 & 24.7 & 227 & 208 \\
\hline 0.95 & 165 & 146 & 74.7 & 44.5 & 204 & 188 \\
\hline 1.9 & 125 & 109 & 52.4 & 28.3 & 148 & 127 \\
\hline
\end{tabular}

XRD patterns of the Mn-3.7/C-250 and C-250 are provided in Fig. 3(c). Peak positions of ramsdellite phase are provided in the same figure for comparison. There are two characteristic peaks around 37 and 65 degrees for Mn-3.7/C-250, which corresponds to the (021) and (061) planes of ramsdellite, but the other ramsdellite peaks are very weak and cannot be clearly observed. Chabre and some other researchers reported that the electrochemically-prepared $\mathrm{MnO}_{2}$ preferentially grows perpendicular to the (021) and (061) planes with a large concentration of structural defects called microtwinning. ${ }^{31-33}$ The chemical defects of microtwinning are known to be compensated by $\mathrm{OH}^{-} / \mathrm{O}^{2-}$ in twinned boundaries.

XPS results also indicate the existence of a large amount of structural water in the $\mathrm{MnO}_{2} \mathrm{NWs}$ as discussed in ESI (Table S2 and Fig. S2 $\dagger){ }^{31}$ In addition, the continuous twinning of the crystal phase was clearly observed in the deposited $\mathrm{MnO}_{2} \mathrm{NWs}$ through high-magnification TEM analysis (Fig. 3(b)). This also supports the fact that the axis of $\mathrm{MnO}_{2} \mathrm{NWs}$ would correspond either to the direction (021) or (061), and $\mathrm{MnO}_{2} \mathrm{NWs}$ contain a number of twin boundaries.

\section{Electrochemical measurements of $\mathrm{MnO}_{2} \mathrm{NW} / \mathrm{CNF}$ composite electrodes}

Fig. 4(a) and (b) show the charge-discharge curves of Mn/C-250s and $\mathrm{Mn} / \mathrm{C}-650 \mathrm{~s}$ with various mass loadings at a current density of $0.5 \mathrm{~A} \mathrm{~g}^{-1}$, respectively. All the $\mathrm{MnO}_{2} \mathrm{NW} / \mathrm{CNF}$ composite electrodes show triangular curves: the larger amount of $\mathrm{MnO}_{2}$ NW-deposited electrode shows a smaller slope than unmodified CNF electrodes, demonstrating better capacitance.

The specific gravimetric capacitance for total electrode mass $\left(C_{\mathrm{g}}\right)$ and deposited $\mathrm{MnO}_{2} \mathrm{NWs}\left(C_{\mathrm{g}}-\mathrm{MnO}_{2}\right)$, and the specific volumetric capacitance for apparent volume of electrode $\left(C_{\mathrm{v}}\right)$

Table 3 The internal structural characteristics of $\mathrm{Mn}-0.95 / \mathrm{C}-250$ and $\mathrm{Mn}-0.95 / \mathrm{C}-650$ composite electrodes

\begin{tabular}{lll}
\hline Electrode & Average pore size $^{a}(\mu \mathrm{m})$ & Porosity $^{a}(\%)$ \\
\hline C-250 & 0.83 & 61 \\
C-650 & 2.69 & 57 \\
Mn-0.95/C-250 & 0.12 & 34 \\
Mn-0.95/C-650 & 2.72 & 63
\end{tabular}

${ }^{a}$ Determined by mercury porosimetry measurements in the pore size ranging from $3 \mathrm{~nm}$ to $10 \mu \mathrm{m}$. 
(a)

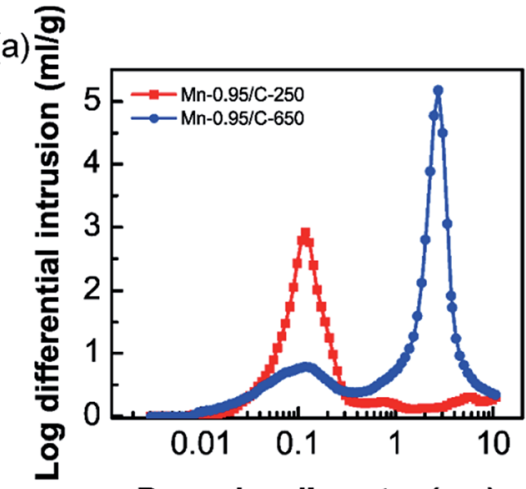

(b)

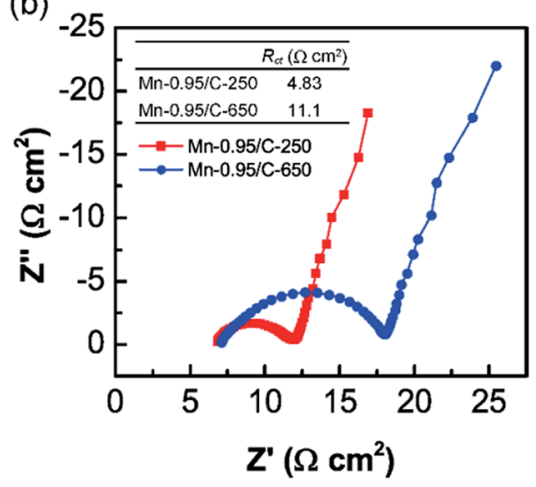

Fig. 5 (a) Pore size distributions of Mn-0.95/C-250 and Mn-0.95/C-650 electrodes in the range from $3.0 \mathrm{~nm}$ to $10 \mu \mathrm{m}$. (b) Nyquist plots of Mn0.95/C-250 and Mn-0.95/C-650 electrodes.

(the definitions are included in the ESI $\dagger$ ) were evaluated by galvanostatic charge/discharge measurements as shown in Table 2. The Mn-0.95/C-250 electrode showed the highest $C_{\mathrm{g}}$ of $165 \mathrm{~F} \mathrm{~g}^{-1}$, which is better than the reported $C_{\mathrm{g}}$ of $120-150 \mathrm{~F} \mathrm{~g}^{-1}$ for the $\mathrm{MnO}_{2} /$ carbon composite electrodes including $\mathrm{MnO}_{2}$ nanofiber/carbon nanosphere, $\mathrm{MnO}_{2}$ nanoparticle/CNT, and $\mathrm{MnO}_{2}$ nanoflower/graphene electrodes. ${ }^{16,34,35} \mathrm{Mn} / \mathrm{C}-250$ s show higher gravimetric and volumetric capacitances than those of $\mathrm{Mn} / \mathrm{C}-650 \mathrm{~s}$ at all the mass loadings. In addition, $\mathrm{Mn} / \mathrm{C}-250 \mathrm{~s}$ and $\mathrm{Mn} / \mathrm{C}-650 \mathrm{~s}$ show the maximum value of $C_{\mathrm{g}}$ and $C_{\mathrm{v}}$ at the mass loading of $0.95 \mathrm{mg} \mathrm{cm}{ }^{-2}$. This can be explained by the assumption that the electrochemically utilizations of $\mathrm{MnO}_{2}$ NWs were substantially decreased at the mass loading of $1.9 \mathrm{mg}$ $\mathrm{cm}^{-2}$ due to its small electric conductivities. The assumption was supported by a relatively large decrease in $C_{\mathrm{g}}-\mathrm{MnO}_{2}$ at the greater mass loading of $\mathrm{MnO}_{2}$.

The difference in the capacitances between $\mathrm{Mn} / \mathrm{C}-250$ s and $\mathrm{Mn} / \mathrm{C}-650$ s more significantly appeared in volumetric capacitance than in gravimetric one. It would be due to the contribution of the internal structure of the $\mathrm{MnO}_{2} \mathrm{NW} / \mathrm{CNF}$ composite electrodes. To further investigate the structure-capacitance relationship of the $\mathrm{MnO}_{2} \mathrm{NW} / \mathrm{CNF}$ composite electrodes, the internal structural characteristics of the Mn-0.95/C-250 and the Mn-0.95/C-650 are summarized in Table 3 (pore size distribution is also shown in Fig. 5(a)). For the Mn-0.95/C-250, only a large number of nanosized pores, which correspond to the interspace between the $\mathrm{MnO}_{2}$ NWs, appeared. For the Mn-0.95/C-650, on the other hand, both a small number of nanosized pores and a large number of microsized pores, which correspond to the

(a) $\mathrm{C}-250$

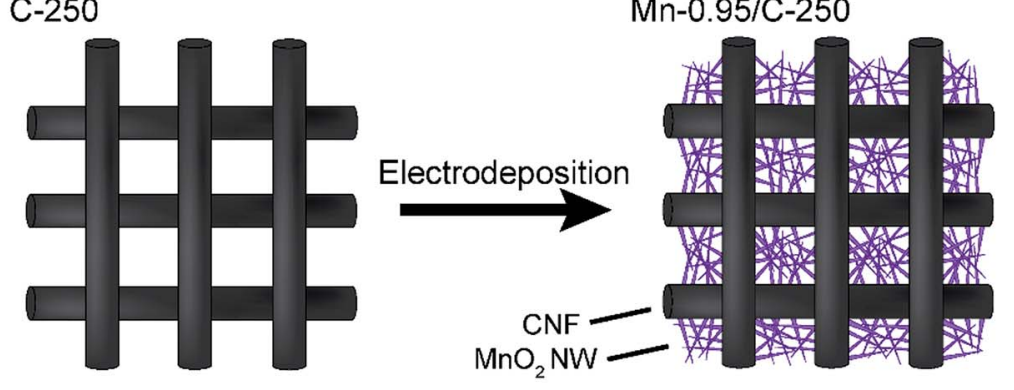

(b) $\mathrm{C}-650$

$\mathrm{Mn}-0.95 / \mathrm{C}-650$

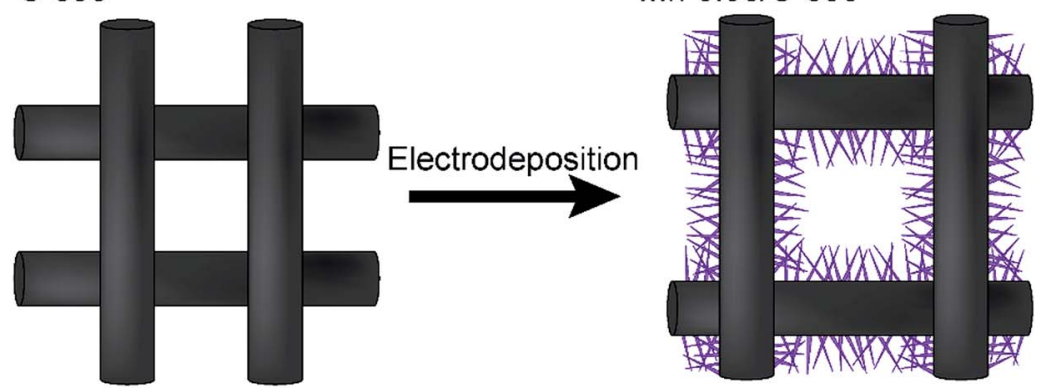

Fig. 6 (a and b) Schematics of the internal structures of the CNF electrodes before and after electrochemical deposition of $\mathrm{MnO}_{2} \mathrm{NWs}$ for $\mathrm{C}-250$ and C-650, respectively. 
interspaces between the $\mathrm{MnO}_{2}$ NWs and surface-modified CNFs, respectively, appeared. As shown in Table 3, after electrodeposition of $\mathrm{MnO}_{2} \mathrm{NWs}$, the pore size of the C-250 decreased from $0.83 \mu \mathrm{m}$ to $0.12 \mu \mathrm{m}$ while that of C-650 was slightly increased from $2.69 \mu \mathrm{m}$ to $2.72 \mu \mathrm{m}$. In addition, the porosity of the C-250 significantly decreased by the electrodeposition of $\mathrm{MnO}_{2} \mathrm{NWs}$, but that of C-650 was slightly increased from $57 \%$ to $63 \%$ as well as pore size (the $\mathrm{MnO}_{2} \mathrm{NW}$ layer deposited on C-650 framework enlarge the inter-fiber space. This behaviour was also confirmed by the thickness change of the electrodes, see Fig. S3†). These internal structural changes are due to the difference in the hierarchical nanostructure between $\mathrm{Mn} / \mathrm{C}-250$ and Mn/C-650 composite electrodes: for the $\mathrm{Mn}-0.95 / \mathrm{C}-250$, the $\mathrm{MnO}_{2} \mathrm{NWs}$ form a network nanostructure in the CNF framework because of its narrow inter-fiber space.

Based on these structural characteristics, the findings that Mn-0.95/C-250 showed higher capacitance than Mn-0.95/C-650 could be explained by the following assumptions. At the high mass loading of $\mathrm{Mn} / \mathrm{C}-250$, formation of more densely network structure of $\mathrm{MnO}_{2} \mathrm{NWs}$ in the CNF framework would enhance electrochemically utilization efficiency of $\mathrm{MnO}_{2}$ (Fig. 6(a)). On the contrary, at the high mass loading of $\mathrm{Mn} / \mathrm{C}-650$, the thick $\mathrm{MnO}_{2}$ NW layer with small electric conductivities ${ }^{6,32}$ would reduce electrochemically utilization efficiency of $\mathrm{MnO}_{2}$ (Fig. 6(b)). This is also supported by electrochemical impedance measurements: the charge transfer resistances $\left(R_{\mathrm{ct}}\right)$ of the $\mathrm{Mn}-0.95 / \mathrm{C}-250$ is lower than half of that of the Mn-0.95/C-650 (Fig. 5(b)).

\section{Fabrication and evaluation of the asymmetric supercapacitor}

To confirm an applicability of the $\mathrm{MnO}_{2}$ NW/CNF composite electrodes for the supercapacitor electrode, an ASC device was fabricated and the device performance was evaluated. The device configuration is schematically shown in Fig. 7(a). Mn0.95/C-250 electrode, AC, and $1 \mathrm{M} \mathrm{Na}_{2} \mathrm{SO}_{4}$ solution were used as the positive electrode, the negative electrode and the electrolyte, respectively. As shown in Fig. 7(b), the ASC operated at a voltage window of $1.6 \mathrm{~V}$ and achieved a capacitance of $25.1 \mathrm{~F}$ $\mathrm{g}^{-1}$ at a current density of $1.0 \mathrm{~A} \mathrm{~g}^{-1}$. This result compares with the previous works: $\mathrm{MnO}_{2}$ nanopowder and AC electrodes $(22 \mathrm{~F}$ $\mathrm{g}^{-1}$ at $\left.1.1 \mathrm{~A} \mathrm{~g}^{-1}\right), \mathrm{MnO}_{2}$ nanofiber/carbon nanosphere and carbon nanosphere electrodes $\left(24.5 \mathrm{~F} \mathrm{~g}^{-1}\right.$ at $\left.1.0 \mathrm{~A} \mathrm{~g}^{-1}\right)$, and $\mathrm{MnO}_{2}$ nanopowder and graphene electrodes (about $27 \mathrm{~F} \mathrm{~g}^{-1}$ at 1.0 $\left.\mathrm{A} \mathrm{g}^{-1}\right){ }^{16,36,37}$ The energy and power densities (the definitions are included in the ESI $\dagger$ ) of the ASC showed high values of 8.9 $\mathrm{W} \mathrm{h} \mathrm{kg}{ }^{-1}$ and $4.9 \mathrm{~kW} \mathrm{~kg}^{-1}$ at $1.0 \mathrm{~A} \mathrm{~g}^{-1}$, respectively. For comparison with other ASCs prepared with $\mathrm{MnO}_{2}$ and carbonaceous materials, the Ragone plot is shown in Fig. 7 (c). ${ }^{\mathbf{1 0 , 1 6 , 3 7 - 4 0}}$ Fig. 7(d) shows the cyclic performance and coulombic efficiency of the ASC at a current density of $1.0 \mathrm{~A} \mathrm{~g}^{-1}$. This device showed a capacitance retention of $80 \%$ and high coulombic efficiency $(>99 \%)$ after 2000 cycles. The decrease in capacitance would derive from the morphological change in the $\mathrm{MnO}_{2} \mathrm{NWs}$ on the positive electrode because the AC negative electrode have good cycle stability ( $>97 \%$ after 2000 cycles). Fig. S4† shows the SEM image of Mn-0.95/C-250 electrode after 2000 cycles. The as- (a)

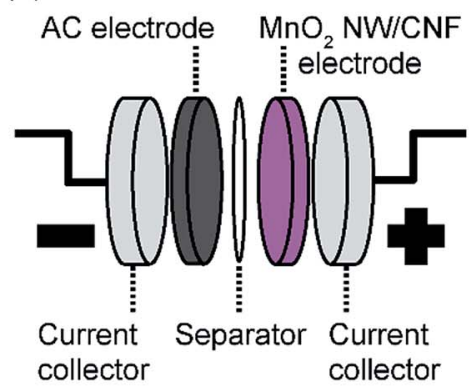

Electrolyte: $1 \mathrm{M} \mathrm{Na}_{2} \mathrm{SO}_{4}$

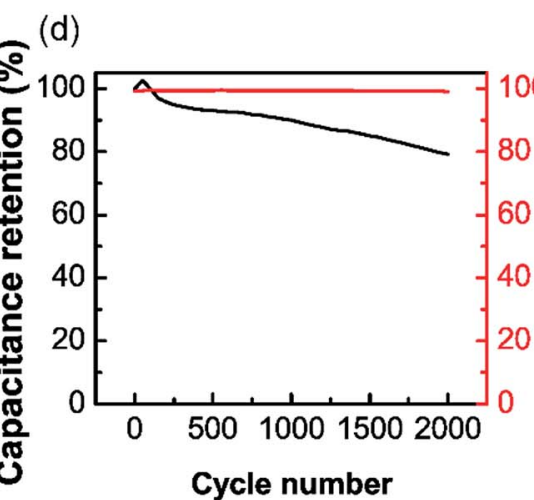

(b)

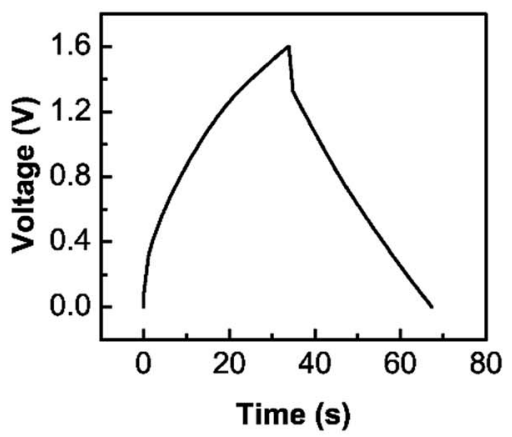

(e) (c)

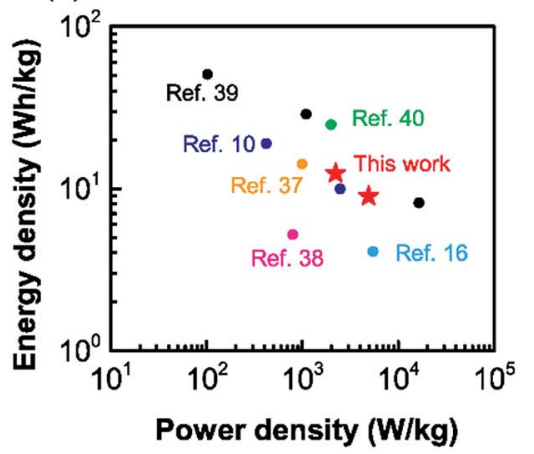

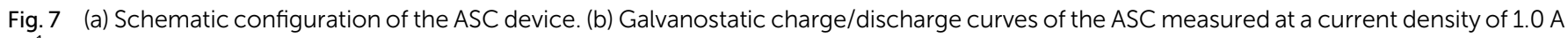

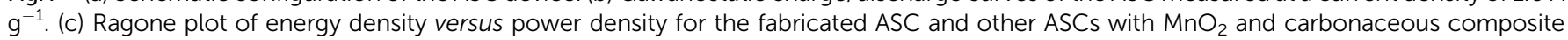

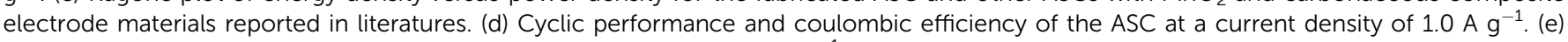
Nyquist plots of the ASC during cycling test at a current density of $1.0 \mathrm{~A} \mathrm{~g} \mathrm{~g}^{-1}$. 
prepared $\mathrm{MnO}_{2}$ NWs were converted into a film-like structure at the electrolyte interface. Nyquist plots of the ASC during cycling test at a current density of $1.0 \mathrm{~A} \mathrm{~g}^{-1}$ are shown in Fig. 7(e). After 500 cycles, a new constant inclination $\left(45^{\circ}\right.$ angle) region clearly appears in low-frequency range. The appearance of this region indicates the increase in diffusion length of ions and support the morphological change in the $\mathrm{MnO}_{2}$ NWs. ${ }^{\mathbf{4 1 4 2}}$ This morphological change would be caused by slow dissolution and re-deposition of $\mathrm{MnO}_{2}$ during the electrochemical oxidation/ reduction cycles and lead to a decrease in both the effective surface area and electric conductivities of the $\mathrm{MnO}_{2}$. For the practical use of the $\mathrm{MnO}_{2} \mathrm{NW} / \mathrm{CNF}$ composite electrodes, it will be a crucial issue to prevent the morphological change during the electrochemical oxidation/reduction cycles. Pang pointed out that the structural water in $\mathrm{MnO}_{2}$ decrease the cycle stability. ${ }^{3}$ As mentioned above $\mathrm{MnO}_{2}$ NWs contain a large number of structural water. A thermal treatment is a possible approach to improve the cycling stability.

\section{Conclusions}

In the present study, hierarchically nanostructured composite electrodes were prepared by the electrodeposition of $\mathrm{MnO}_{2} \mathrm{NWs}$ on the electrospun CNF webs and the structure-property relationship of the $\mathrm{MnO}_{2} \mathrm{NW} / \mathrm{CNF}$ composite electrodes was investigated. The internal structure of the composite electrodes depended on CNF diameter (or inter-fiber space of CNF framework) and loading amount of $\mathrm{MnO}_{2} \mathrm{NWs}$ : at a large mass loading of $\mathrm{MnO}_{2}$, the deposited $\mathrm{MnO}_{2}$ NWs form a network nanostructure between the interconnected C-250 framework, while a thicker $\mathrm{MnO}_{2} \mathrm{NW}$ layer was formed on the CNF surface in the C-650 framework. The electrodes based on the hierarchical structure composed of CNF framework and $\mathrm{MnO}_{2} \mathrm{NW}$ network showed high gravimetric and volumetric capacitances. An asymmetric supercapacitor shows high energy and power densities of $8.9 \mathrm{~W} \mathrm{~h} \mathrm{~kg}^{-1}$ and $4.9 \mathrm{~kW} \mathrm{~kg}^{-1}$, respectively, and $80 \%$ capacitance retention and high coulombic efficiency (>99\%) over 2000 cycles. This result clearly suggests hierarchical network nanostructure composed of an active material and a charge collector enhance the electrochemically utilization efficiency of $\mathrm{MnO}_{2}$ on the electrode surface. These findings provide a useful guide in design of efficient electrochemical device electrodes including supercapacitors.

\section{Acknowledgements}

This study was partly supported by the fund for the Development of Human Resources in Science and Technology of the Japan Science and Technology Agency, JST (for H. M.) and a Grant-in-Aid for JSPS Research Fellows (No. 15J12492) by JSPS KAKENHI (for Y. S.). The authors appreciate the kind support of Mr Jun Koki, Mr Akira Genseki, and Mr Hiroshi Iida, Center for Advanced Materials Analysis, Tokyo Institute of Technology, for the SEM observations, TEM observations, and XRD measurements, respectively; and Dr Yuta Nabae, Department of Materials Science and Engineering, Tokyo Institute of Technology, for the XPS measurements.

\section{References}

1 D. Galizzioli, F. Tantardini and S. Trasatti, J. Appl. Electrochem., 1974, 4, 57-67.

2 S. Trasatti and G. Buzzanca, J. Electroanal. Chem. Interfacial Electrochem., 1971, 29, A1-A5.

3 S. Pang, M. A. Anderson and T. W. Chapman, J. Electrochem. Soc., 2000, 147, 444-450.

4 H. Y. Lee and J. B. Goodenough, J. Solid State Chem., 1999, 148, 81-84.

5 V. Srinivasan and J. W. Weidner, J. Electrochem. Soc., 1997, 144, L210-L213.

6 M. Toupin, T. Brousse and D. Bélanger, Chem. Mater., 2004, 16, 3184-3190.

7 J. N. Broughton and M. J. Brett, Electrochim. Acta, 2005, 50, 4814-4819.

8 C. Xu, F. Kang, B. Li and H. Du, J. Mater. Res., 2010, 25, 14211432.

9 J. Kang, A. Hirata, L. Kang, X. Zhang, Y. Hou, L. Chen, C. Li, T. Fujita, K. Akagi and M. Chen, Angew. Chem., Int. Ed., 2013, 52, 1664-1667.

10 M. Huang, Y. Zhang, F. Li, L. Zhang, R. S. Ruoff, Z. Wen and Q. Liu, Sci. Rep., 2014, 4, 3878.

11 Q. Tang, M. Chen, C. Yang, W. Wang, H. Bao and G. Wang, ACS Appl. Mater. Interfaces, 2015, 7, 15303-15313.

12 T. G. Yun, B. il Hwang, D. Kim, S. Hyun and S. M. Han, ACS Appl. Mater. Interfaces, 2015, 7, 9228-9234.

13 T. Zhai, F. Wang, M. Yu, S. Xie, C. Liang, C. Li, F. Xiao, R. Tang, Q. Wu, X. Lu and Y. Tong, Nanoscale, 2013, 5, 6790-6796.

14 G. Yu, L. Hu, M. Vosgueritchian, H. Wang, X. Xie, J. R. McDonough, X. Cui, Y. Cui and Z. Bao, Nano Lett., 2011, 11, 2905-2911.

15 J. Liu, J. Essner and J. Li, Chem. Mater., 2010, 22, 5022-5030.

16 Z. Lei, J. Zhang and X. S. Zhao, J. Mater. Chem., 2012, 22, 153160.

17 M.-S. Wu, Z.-S. Guo and J.-J. Jow, J. Phys. Chem. C, 2010, 114, 21861-21867.

18 L. Hu, W. Chen, X. Xie, N. Liu, Y. Yang, H. Wu, Y. Yao, M. Pasta, H. N. Alshareef and Y. Cui, ACS Nano, 2011, 5, 8904-8913.

19 P. Li, Y. Yang, E. Shi, Q. Shen, Y. Shang, S. Wu, J. Wei, K. Wang, H. Zhu, Q. Yuan, A. Cao and D. Wu, ACS Appl. Mater. Interfaces, 2014, 6, 5228-5234.

20 M. Yang, K. G. Lee, S. J. Lee, S. B. Lee, Y.-K. Han and B. G. Choi, ACS Appl. Mater. Interfaces, 2015, 7, 22364-22371.

21 J. Deng, X. Wang, X. Duan and P. Liu, ACS Sustainable Chem. Eng., 2015, 3, 1330-1338.

22 B. Shen, J. Lang, R. Guo, X. Zhang and X. Yan, ACS Appl. Mater. Interfaces, 2015, 7, 25378-25389.

23 Y. Cheng, S. Lu, H. Zhang, C. V. Varanasi and J. Liu, Nano Lett., 2012, 12, 4206-4211.

24 Y. Jin, H. Chen, M. Chen, N. Liu and Q. Li, ACS Appl. Mater. Interfaces, 2013, 5, 3408-3416.

25 A. Greiner and J. H. Wendorff, Angew. Chem., Int. Ed., 2007, 46, 5670-5703. 
26 D. Li and Y. Xia, Adv. Mater., 2004, 16, 1151-1170.

27 D. H. Reneker and A. L. Yarin, Polymer, 2008, 49, 2387-2425.

28 A. Krueger, Carbon Materials and Nanotechnology, Wiley-VCH Verlag GmbH \& Co. KGaA, Weinheim, Germany, 2010.

29 H. Matsumoto, S. Imaizumi, Y. Konosu, M. Ashizawa, M. Minagawa, A. Tanioka, W. Lu and J. M. Tour, ACS Appl. Mater. Interfaces, 2013, 5, 6225-6231.

30 S. Imaizumi, H. Matsumoto, K. Suzuki, M. Minagawa, M. Kimura and A. Tanioka, Polym. J., 2009, 41, 1124-1128.

31 Y. Chabre and J. Pannetier, Prog. Solid State Chem., 1995, 23, 1-130.

32 P. Ruetschi, J. Electrochem. Soc., 1984, 131, 2737-2744.

33 P. Ruetschi and R. Giovanoli, J. Electrochem. Soc., 1988, 135, 2663-2669.

34 M. Narubayashi, Z. Chen, K. Hasegawa and S. Noda, RSC Adv., 2016, 6, 41496-41505.
35 Y. He, W. Chen, X. Li, Z. Zhang, J. Fu, C. Zhao and E. Xie, ACS Nano, 2013, 174-182.

36 T. Brousse, M. Toupin and D. Bélanger, J. Electrochem. Soc., 2004, 151, A614-A622.

37 A. Mery, F. Ghamouss, C. Autret, D. Farhat and F. Tran-Van, J. Power Sources, 2016, 305, 37-45.

38 Y. S. Wang, D. S. Tsai, W. H. Chung, Y. S. Syu and Y. S. Huang, Electrochim. Acta, 2012, 68, 95-102.

39 Z. Fan, J. Yan, T. Wei, L. Zhi, G. Ning, T. Li and F. Wei, Adv. Funct. Mater., 2011, 21, 2366-2375.

40 P. Shang, J. Zhang, W. Tang, Q. Xu and S. Guo, Adv. Funct. Mater., 2016, 26, 7766-7774.

41 W. Sugimoto, H. Iwata, K. Yokoshima, Y. Murakami and Y. Takasu, J. Phys. Chem. B, 2005, 109, 7330-7338.

42 S.-E. Chun, S.-I. Pyun and G.-J. Lee, Electrochim. Acta, 2006, 51, 6479-6486. 